\title{
Projetos futuros de adolescentes privados de liberdade: implicações para o processo socioeducativo
}

\author{
Katia Simone da Silva Silveira' \\ Universidade Federal de Santa Maria, Santa Maria - RS - Brasil \\ Jéssica Costa Machado \\ Faculdade Integrada de Santa Maria, Santa Maria - RS - Brasil \\ Jana Gonçalves Zappe \\ Ana Cristina Garcia Dias \\ Universidade Federal do Rio Grande do Sul, Porto Alegre - RS - Brasil
}

\begin{abstract}
Resumo: A relação entre a medida socioeducativa de internação e os projetos futuros de adolescentes autores de atos infracionais é aspecto central para a superação da condição de vulnerabilidade associada à prática de atos infracionais. Este trabalho buscou, por meio de um estudo de casos múltiplos, investigar os projetos futuros de adolescentes privados de liberdade para cumprimento de medida socioeducativa. Os adolescentes investigados apresentaram projetos futuros diferenciados, os quais envolveram aspectos positivos (família, trabalho, estudo e aquisição de bens materiais), negativos (vingança) e de indefinição. Adolescentes com projetos futuros positivos precisam ser incentivados e receber suporte para a efetivação desses planos, enquanto adolescentes com projetos indefinidos ou negativos necessitam de atenção para superar essa condição e elaborar projetos positivos. Esses resultados reforçam a necessidade de oferecer um atendimento individualizado, considerando as peculiaridades de cada caso, e a importância da articulação entre programas socioeducativos e políticas de educação, profissionalização, trabalho e renda.
\end{abstract}

Palavras-chave: adolescentes; institucionalização; expectativas; projeto de vida; delinquentes juvenis.

\section{FUTURE PROJECTS OF ADOLESCENTS DEPRIVED OF FREEDOM: IMPLICATIONS FOR THE SOCIO-EDUCATIVE PROCESS}

\begin{abstract}
The relationship between the socio-educacional rehabilitation imprisonmet and future projects of adolescents who committed offenses is central to overcome the vulnerability condition associated with the practice of offenses. This study aimed to investigate, through a multiple cases study, the future projects of adolescents deprived of freedom for socio-educational rehabilitation. The aforementioned adolescents presented different future projects that involved positives aspects (family, work, study and acquisition of material goods), negative (revenge) and uncertainty. Adolescents with positive future projects need to be encouraged and supported to accomplish them, while adolescents with negative or uncertain projects need attention to overcome this condition and to develop positive projects. These results reinforce the need to provide individualized care, considering the peculiarities of each case, and the importance of the articulation among socio-educational programs and policies concerning education, professionalization, work and income.
\end{abstract}

Keywords: adolescents; institutionalization; expectations; life project; juvenile delinquents.

1 Endereço para correspondência: Katia Simone da Silva Silveira, Universidade Federal de Santa Maria, Rua Marechal Floriano Peixoto, 1.750, $3^{\circ}$ andar, sala 300, Centro - Santa Maria - RS - Brasil. CEP: 97015-370. E-mail: ksmhd@hotmail.com. 
PROYECTOS FUTUROS DE ADOLESCENTES PRIVADOS DE LIBERTAD: IMPLICACIONES PARA EL PROCESO SOCIO-EDUCATIVO

\begin{abstract}
Resumen: La relación entre la rehabilitación social y educativa de internamiento y los proyectos futuros de adolescentes que han cometido delitos es fundamental para la superación de la condición de vulnerabilidad asociada a la práctica de infracciones. Este trabajo buscó, mediante un estudio de casos múltiples, la investigación de los proyectos futuros de adolescentes internados para rehabilitación social y educativa. Los adolescentes presentaron diferentes proyectos de futuro, que involucraron aspectos positivos (familia, trabajo, estudio y adquisición de bienes materiales), negativos (la venganza) y de incertidumbre. Adolescentes con proyectos de futuro positivos deben ser alentados y apoyados para su éxito, mientras que los adolescentes con proyectos inciertos o negativos necesitan atención con el fin de superar esta condición y desarrollar proyectos positivos. Estos resultados refuerzan la necesidad de proporcionar una atención individualizada, teniendo en cuenta las peculiaridades de cada caso, así como la importancia de la relación entre los programas socio-educativos y las políticas de educación, la formación profesional, el empleo y la renta.
\end{abstract}

Palabras clave: adolescentes; institucionalización; expectativas; proyecto de vida; delincuentes juveniles.

A adolescência é um momento do desenvolvimento caracterizado como uma fase de transição para a vida adulta. Nela, ocorre uma série de mudanças, que incluem desde as transformações corporais até alterações significativas nas relações com as pessoas com as quais o adolescente convive (Andrade, 2010). O fim da adolescência caracteriza-se pela definição de papéis sociais relacionados com o exercício da vida adulta, que podem incluir papéis familiares e profissionais, por exemplo. Nesse sentido, é na adolescência que se constroem, se consolidam e se definem projetos futuros, os quais são simultaneamente uma construção interna e externa, pois envolvem tanto aspectos pessoais quanto aspectos das relações interpessoais estabelecidas e ainda do contexto social mais amplo (Liebesny \& Ozella, 2002).

Para Marcelino, Catão e Lima (2009), um projeto de futuro reúne um conjunto de anseios que se pretende realizar por meio de etapas a serem ultrapassadas rumo a um ideal pretendido, o que permite a organização e a orientação em direção à sua realização no futuro. Um projeto futuro é elaborado tanto a partir das experiências passadas como pelas influências e pelo envolvimento em atividades desenvolvidas no presente. Esses fatores podem promover ou prejudicar a conquista do projeto de futuro.

Os projetos futuros são elaborados por meio das experiências pessoais, sociais e culturais, sendo interpretados conforme as interações do indivíduo com essas vivências. Assim, esses projetos são, ao longo da vida, modificados/transformados de acordo com a história de cada indivíduo e com base nas relações estabelecidas com os outros, portanto os projetos não são inflexíveis, pois estão em permanente adaptação ao longo do desenvolvimento (Teixeira, 2005).

A educação, o trabalho e a família são os principais aspectos presentes nos projetos futuros de adolescentes, no entanto eles são influenciados pelas condições socioeconômicas e culturais presentes nos contextos em que os adolescentes se desenvolvem, uma vez que as oportunidades são vistas por meio das condições sociais concretas que 
a família e a comunidade oferecem (Sobrosa, Santos, Oliveira, \& Dias, 2014). Esse é um aspecto particularmente relevante para a compreensão dos projetos futuros de adolescentes em conflito com a lei, uma vez que grande parte deles vivenciou uma realidade marcada por desigualdades sociais, sendo excluídos dos espaços de cultura, lazer e educação. Esses aspectos favorecem a vulnerabilidade social e a inclusão no mundo do crime, da violência e da privação de liberdade, a qual é, muitas vezes, marcada pela oferta de um acompanhamento social precário (Sartório \& Rosa, 2010).

Dessa forma, compreende-se que uma situação socioeconômica desfavorável, caracterizada pela exclusão social, pode desencorajar a construção de projetos futuros, pois a privação material, a degradação moral, a incerteza quanto ao futuro e a desilusão com o progresso geram desesperança. Nesses casos, o adolescente poderá ter dificuldades para investir no desenvolvimento escolar, almejar a profissionalização e inserir-se no mercado de trabalho, em função da escassez de oportunidades oferecidas aos mais desfavorecidos socioeconomicamente. Nessas situações, o envolvimento com a criminalidade pode ser vista como uma alternativa, tornando as escolhas futuras arriscadas (Paugam, 2004).

Como a criminalidade juvenil tem aumentado de forma exacerbada nos últimos anos, essa problemática tornou-se tema de diversos debates acadêmicos (Aranzedo \& Souza, 2007; Assis \& Constantino, 2005; Muller, Barboza, Oliveira, Santos, \& Paludo, 2009). Processos de marginalização e de exclusão social têm sido associados com a prática de atos infracionais por adolescentes, uma vez que a baixa renda, a escolaridade precária e as dificuldades de acesso a trabalho e renda impedem que os adolescentes sejam reconhecidos com sujeito de direitos, o que também ocorre com as famílias deles (Assis \& Constantino, 2005). Desse modo, a problemática do adolescente em conflito com a lei pode ser identificada como uma forma de comunicar aquilo que não pode ser expresso de outra forma, denunciando dificuldades e assinalando desigualdades sociais, falta de oportunidades e injustiças no sistema social.

Estudo realizado por Muller et al. (2009) investigou as perspectivas de adolescentes em conflito com a lei sobre o delito, a medida socioeducativa e as expectativas futuras, apontando dificuldades com relação a educação e trabalho como projetos futuros. $\mathrm{Na}$ maioria dos casos, os jovens que participaram do estudo possuíam baixa escolaridade e haviam se evadido da escola. Mesmo aqueles que estudavam antes da internação com frequência não compareciam às aulas. Esses aspectos denunciam a exclusão do contexto escolar, o que promove a vulnerabilidade para o envolvimento em delitos. A educação formal foi vista como uma perspectiva de futuro para $45 \%$ dos participantes do estudo, porém os adolescentes percebem como distante a realização desse desejo ante a realidade de exclusão que vivenciavam antes da internação. Para grande parte deles (56\%), o trabalho é o projeto mais almejado para o futuro, pois muitos necessitam ajudar no provimento da família. Porém, apesar de considerar o trabalho como um projeto futuro, a maioria dos adolescentes não tem metas claras, o que demonstra a falta de conhecimento sobre os caminhos necessários para que possam conseguir um trabalho, embora aspirem a ele (Muller et al., 2009). 
Em função da compreensão de que essas dificuldades decorrentes de processos de exclusão social estão relacionadas com a prática de atos infracionais por adolescentes, as medidas socioeducativas têm um objetivo claro de promover inclusão social e garantia de direitos, auxiliando o jovem e suas famílias a superar as condições de exclusão. Dessa forma, entende-se a medida socioeducativa como uma ação pedagógica que visa à reeducação e à prevenção de reincidência por meio da reconstrução dos projetos futuros de adolescentes em conflito com a lei (Lei n. 8.069, 1990). No Brasil, o Sistema Nacional Socioeducativo (Sinase) é a política pública que regulamenta as diretrizes para a execução de medidas socioeducativas e propõe ações desde a descoberta do ato infracional até o cumprimento propriamente dito da medida, as quais incluem acesso à educação, profissionalização, trabalho, entre outros aspectos. Por meio desse sistema, vários serviços podem se integrar, agilizando a garantia da proteção social e visando à construção e implementação de projetos futuros que possam minimizar a exclusão social que muitos vivenciam (Brasil, 2006).

De fato, encontra-se na literatura o relato de algumas experiências socioeducativas que foram bem-sucedidas na promoção de inclusão social e no resgate da cidadania dos adolescentes, o que previne a reincidência. Essas experiências foram marcadas pelo estabelecimento de relações pessoais significativas entre adolescentes e profissionais, pela aproximação entre o contexto socioeducativo e o contexto comunitário, e, ainda, pela inserção dos adolescentes em outros espaços, como a universidade (Costa, 2005). Assim, ressalta-se que as medidas socioeducativas devem permitir ao adolescente novas oportunidades de inserção social, de estabelecimento de relações interpessoais e de conhecimento do mundo, o que auxilia a construção de projetos futuros positivos e desvinculados da criminalidade (Aranzedo \& Souza, 2007).

No entanto, para que o processo socioeducativo seja efetivo, devem-se considerar as necessidades de cada adolescente e avaliar as reais possibilidades de inserção social, oferecendo suporte para que isso ocorra. Nesse processo, todas as atividades propostas durante o cumprimento de uma medida socioeducativa, bem como todos os relacionamentos estabelecidos com o adolescente, devem visar à finalidade educativa e ressocializadora, o que só ocorrerá se for possível contemplar as demandas dos adolescentes. Com relação aos projetos futuros dos adolescentes, torna-se necessário considerar as significações atribuídas à vinculação e à desvinculação com a prática infracional, assim como as possibilidades de realização de escolhas e de construção de uma nova trajetória de vida. Para isso, é fundamental ouvir os adolescentes, conhecer a trajetória de vida deles, identificar as percepções sobre o contexto socioeducativo e as expectativas quanto ao futuro (Costa, 2005).

Com base nessas considerações, o presente estudo investigou as percepções de adolescentes em conflito com a lei acerca de seus projetos futuros. Buscou-se identificar os aspectos presentes nesses planos e as necessidades para concretizá-los, uma vez que este trabalho se constitui em um aspecto central do processo socioeducativo. 


\section{Método}

A pesquisa utilizou um delineamento de estudo de casos múltiplos, considerada como a estratégia mais adequada para responder à questão de pesquisa proposta, resumida no objetivo geral de investigar as percepções de adolescentes em conflito com a lei a respeito de seus projetos futuros. Trata-se de um fenômeno atual e contemporâneo à vida dos adolescentes em conflito com a lei, alvos da pesquisa. Nesse sentido, como pesquisadores, não temos controle sobre as varáveis envolvidas, situação em que a realização de estudos de casos é bastante recomendável. Além disso, os estudos de caso se mostram como uma estratégia útil quando se colocam questões do tipo "como" e "por que", sobretudo quando o propósito é conhecer como os adolescentes constroem os próprios projetos futuros ou ainda como estes se relacionam com o conflito legal. Ademais, o estudo de múltiplos casos tem o objetivo de expandir e generalizar teorias. Assim, consistem em variações dentro dos projetos de estudos de caso e são utilizados como estratégia de pesquisa. Nessa técnica, consideram-se todas as estratégias de forma pluralística, em que o pesquisador pode estabelecer seu procedimento de acordo com uma determinada situação, pois são coletadas as informações relevantes sobre cada indivíduo, considerando diversos casos, que podem ser incluídos em uma análise integrada. Assim, são escolhidas proposições (teorias, limitações, redução dos dados relevantes) para ajudar na identificação das informações relevantes desses indivíduos. Sem o uso das proposições, o pesquisador pode ser induzido a coletar materiais desnecessários para determinada pesquisa. Além disso, a opção por um estudo de múltiplos casos deu-se pelo fato de este ser visto como algo mais robusto que o estudo de um caso individual (Yin, 2005).

\section{Participantes}

Participaram do estudo cinco jovens do sexo masculino que estavam privados de liberdade pela prática de ato(s) infracional(is): Igor, 18 anos de idade, interno pela prática de homicídio; Anderson, 18 anos, interno pela prática de tentativa de homicídio; Cristofer, 15 anos, interno pela prática de furtos; Pedro, 16 anos, interno pela prática de furtos; e Tiago, 17 anos, interno pela prática de furtos. Destaca-se que os nomes utilizados para se referir aos casos são fictícios, visando à preservação da identidade dos participantes.

\section{Instrumentos}

A coleta de informações foi realizada durante o ano de 2010 e ocorreu a partir de duas entrevistas individuais guiadas com cada adolescente. Na primeira entrevista, estabeleceu-se o primeiro contato com o adolescente, e os tópicos da entrevista guiada compreendiam aspectos da história de vida pessoal e familiar do jovem. A segunda entrevista abordou aspectos relacionados à prática de atos infracionais, ao cumprimento da medida socioeducativa e aos projetos futuros dos adolescentes. As entrevistas 
foram gravadas em audiotape e posteriormente transcritas para análise. Adotaram-se as providências necessárias para garantia de sigilo e confidencialidade dos dados dos participantes.

\section{Procedimentos}

Foram convidados a participar da pesquisa os adolescentes que estavam internados em uma unidade para cumprimento de medida socioeducativa localizada no interior do Estado do Rio Grande do Sul, após a pesquisa ter sido autorizada pela instituição. Os adolescentes que aceitaram participar do estudo, após receberem orientações sobre os objetivos do estudo e a voluntariedade da participação, assinaram o Termo de Consentimento Livre Esclarecido (TCLE), e, no caso daqueles que tinham idade inferior a 18 anos, foi solicitado também o consentimento dos pais. Adotaram-se todos os procedimentos éticos indicados na Resolução n. 466 (2013). A pesquisa foi aprovada pelo Comitê de Ética em Pesquisa da Universidade Federal de Santa Maria.

A análise das informações foi elaborada por meio da estratégia geral baseada nas proposições teóricas apresentadas, a qual consiste em tomar a orientação teórica que definiu os objetivos da pesquisa como o guia da análise dos casos estudados (Yin, 2005). Assim, depois de transcritas as entrevistas, selecionaram-se todos os trechos em que os adolescentes abordavam aspectos relacionados a seus projetos futuros. Depois de selecionados esses trechos, foi construído um sistema de classificação, em que se agruparam os conteúdos semelhantes dos projetos futuros. Esse processo deu origem a seis categorias temáticas de aspectos relacionados com seus projetos futuros, as quais envolvem: 1. família, 2. trabalho, 3. estudo, 4. aquisição de bens materiais, 5. indefinição e 6. vingança. Observa-se que o sistema de classificação e as categorias criadas emergiram dos dados, e esse processo envolveu o trabalho de duas pesquisadoras que trabalharam de modo simultâneo e independente, visando conferir confiabilidade ao processo. As divergências encontradas foram sanadas por consenso ou pela consulta a um terceiro pesquisador. A seguir, serão descritos os conteúdos dos projetos futuros com base na categorização criada, buscando privilegiar ao máximo a reprodução da fala dos adolescentes, a partir da qual são retomados os conteúdos teóricos.

\section{Resultados}

Uma análise das entrevistas realizadas com os adolescentes identificou seis categorias temáticas de aspectos relacionados com seus projetos futuros, as quais envolvem: 1. família, 2. trabalho, 3. estudo, 4. aquisição de bens materiais, 5. indefinição e 6. vingança. A seguir, esses aspectos serão descritos e ilustrados com a citação de alguns trechos das entrevistas realizadas com os adolescentes.

Os projetos futuros dos adolescentes entrevistados incluem principalmente os temas família e trabalho, uma vez que todos os participantes mencionaram projetos vinculados a questões familiares e três jovens indicaram planos relacionados ao ingresso no 
mercado de trabalho. Com relação à família, os projetos futuros dos adolescentes incluem tanto a constituição de seu próprio núcleo familiar por meio do casamento e da parentalidade quanto o desejo de ajudar o núcleo familiar de origem, envolvendo especialmente a mãe. A construção de uma nova família aparece, por exemplo, quando o adolescente Cristofer se refere à casa que idealiza ter no futuro: "uma meia-água assim, uma caída assim e assim e meia esticada, meia curta. Não precisa ser tão grande, só pra mim e pra minha mulher e pro meu filho tá bom". Com relação à família de origem, Cristofer mencionou: "ajudar minha mãe. Ajudar, só de ajudar minha mãe é cumprir isso aqui. Ela me fala: 'Uma grande ajuda que tu me dá é cumprir e me ajudar lá fora. É uma grande ajuda que tu tá me fazendo'". Além do projeto de ajudar a mãe, o relato desse adolescente evidencia também a presença da mãe no seu cotidiano institucional. Pode-se visualizar que o projeto de ajudar a mãe coloca-se tanto como uma forma de expressar gratidão pelo apoio recebido no presente quanto como uma resposta a um pedido de ajuda realizado pela mãe. Dessa forma, compreende-se que a família é tanto fonte de apoio ao jovem quanto é carente da ajuda do adolescente, revelando o quanto a situação de exclusão social envolve os adolescentes e também suas famílias. Apesar de a família, e especialmente a mãe, ser fonte de apoio ao adolescente, ela mesma se revela carente e desamparada, com poucos recursos para promover a superação da condição de vulnerabilidade que os afeta.

Outro tema bastante presente nos projetos futuros dos adolescentes entrevistados foi o trabalho, aspecto que parece ser visto por eles como central para o afastamento da criminalidade. Três adolescentes relataram o desejo de trabalhar e mudar de vida após o cumprimento da medida socioeducativa. Cristofer, por exemplo, afirma o seguinte: "[pretendo] trabalhar, né?, não adianta... não adianta passar a vida toda roubando, que não é vida". Ele planeja voltar a "trabalhar na estufa. Eu sei. Eu sei trabaIhar de servente. E de estufa, né? Montar estufa", atividades que já exerceu com o pai. Já Tiago pensa em trabalhar após o cumprimento da medida socioeducativa como auxiliar de padeiro, profissão que aprendeu com o tio: "eu gosto da profissão". Apesar de os projetos relacionados ao trabalho serem valorizados e claros, pois os adolescentes mencionam o tipo de trabalho pretendido, observa-se que são atividades que requerem pouco estudo ou qualificação, e provavelmente não são atividades com potencial de levá-los a superar sua condição de exclusão social. Além disso, identificase a família como referência também para o exercício laboral, uma vez que os adolescentes evidenciaram a influência dos familiares em suas atividades de trabalho já exercidas e/ou escolhidas para exercer no futuro.

O número de entrevistados que pretendem retomar os estudos após o cumprimento da medida socioeducativa é menos da metade. O estudo pode ser observado nas falas de Pedro - "Quero estudar e trabalhar [...]" - e Anderson - "estudar e fazer curso". No entanto, são projetos relativamente vagos, pois eles não mencionam metas específicas como o nível de estudo que pretendem obter, que poderia ser a conclusão do ensino médio ou o ingresso no ensino superior, por exemplo, ou quais cursos 
gostariam de cursar, de acordo com seus interesses e aptidões. De fato, a baixa escolaridade dos adolescentes e as dificuldades de acesso à escola e permanência nela fazem com que o estudo não esteja entre os principais projetos para o futuro de adolescentes em conflito com a lei.

A aquisição de bens materiais, como comprar moto e casa, também apareceram no discurso dos adolescentes. Obter uma casa aparece bastante vinculado ao relacionamento familiar, pois os adolescentes mencionaram tanto o desejo de ter uma casa para a família que pretende constituir, o que aparece no relato de Cristofer, já mencionado anteriormente, quanto a vontade de dar uma casa para a família de origem. Além disso, alguns adolescentes, como Tiago, incluem a aquisição de bens materiais como aspectos vinculados a outros projetos, como o trabalho: "quero viver normal, trabalhar e comprá umas coisas pra mim, comprá uma moto pra mim".

Dois participantes apresentaram projetos de futuro como "ser um homem de bem" e "mudar de vida", mas não conseguiram especificá-los em termos mais concretos e com maior clareza. Com isso, expressam um projeto de se desvincular da criminalidade, no entanto necessitam desenvolver metas mais claras que se tornem objetivos a serem atingidos e passíveis de implementação.

Apenas um dos adolescentes, Pedro, relatou um projeto de futuro negativo e vinculado à criminalidade, relacionado a matar alguém para vingar-se da morte do irmão que foi assassinado em um confronto. Quando diz "Eu ainda vou me vingá. Sinto raiva de quem matou ele. Quem matou, eu vou me vingar, primeiro que cair na minha frente, eu vou derrubá", Pedro revela que esse projeto pode ser identificado como uma meta a ser alcançada. A raiva e o desejo de vingança de Pedro são resultados de uma violência extrafamiliar que sofrera pela morte de seu irmão mais velho, que era como um pai para ele. Esse projeto futuro também revela a importância das relações familiares e o quanto estas servem de referências centrais para o desenvolvimento dos projetos futuros dos adolescentes.

\section{Discussões}

A família exerce papel fundamental no desenvolvimento psicossocial de crianças e adolescentes, pois é a instituição responsável pela socialização primária e pode ser fonte tanto de risco como de proteção ao desenvolvimento saudável (Poletto \& Koller, 2008). Neste trabalho, identificou-se que a família é uma referência central para a construção dos projetos futuros dos adolescentes investigados, a qual aparece tanto como fonte de apoio como fator de risco em função de sua própria vulnerabilidade. Diversos estudos com foco na relação entre família e adolescentes em conflito com a lei ressaltaram a importância das relações familiares no desenvolvimento da trajetória infracional (Assis \& Constantino, 2005; Branco, Wagner, \& Demarchi, 2008; Nunes, Andrade, \& Morais, 2013). Além disso, a literatura indica que a família exerce papel central na construção de projetos futuros de adolescentes em geral (Liebesny \& Ozella, 2002). No entanto, não se localizou nenhum estudo que identificasse a importância da 
família no desenvolvimento dos projetos futuros de adolescentes em conflito com a lei, o que evidencia a contribuição inédita do presente estudo.

No relato dos adolescentes investigados, pode-se identificar que a família é uma referência central tanto nos projetos mais positivos de constituir a própria família ou auxiliar a família de origem quanto no projeto mais negativo de vingança pela morte de um familiar. Além disso, também com relação ao trabalho, identifica-se a família como referência nas atividades laborais já exercidas e/ou escolhidas para exercer no futuro. Sendo assim, a família aparece simultaneamente como fonte de proteção e risco na construção dos projetos futuros dos adolescentes investigados. A família pode ser considerada como protetiva à medida que é fonte de apoio e referência para a construção de projetos desvinculados da prática infracional. No entanto, a condição de exclusão vivenciada pelas famílias, aspecto relacionado com a situação de conflito com a lei (Assis \& Constantino, 2005; Muller et al., 2009), também aparece de modo marcante nos relatos dos adolescentes sobre seus projetos futuros, o que configura-se como fator de risco, uma vez que reduz as possibilidades de a família oferecer apoio efetivo. Identifica-se que os projetos manifestados pelos adolescentes são bastante modestos quando descrevem a casa que pretendem adquirir ou os trabalhos que pretendem exercer, por exemplo. Em geral, são trabalhos que não requerem muito estudo ou qualificação e que oferecem baixa remuneração. Dessa forma, oferecem poucas chances de superação da condição de exclusão vivenciada antes do cumprimento da medida socioeducativa (Muller et al., 2009).

As dificuldades com relação à superação da condição de exclusão também se materializam no fato de que poucos adolescentes mencionam o estudo como projeto futuro, e os que mencionam o fazem de modo vago. Diversas pesquisas indicaram que a maioria dos adolescentes em conflito com a lei possui baixa escolaridade e se evadiu da escola, evidenciando uma exclusão do sistema escolar que é anterior à prática de atos infracionais (Assis \& Constantino, 2005; Muller et al., 2009; Zappe \& Ramos, 2010). Os resultados aqui apresentados indicam que as possibilidades de superação da condição de exclusão do sistema de ensino formal são bastante reduzidas, uma vez que praticamente não fazem parte dos projetos futuros relatados pelos adolescentes. Isso também se reflete nas dificuldades de inserção no mercado de trabalho, pois a baixa escolaridade e a falta de qualificação e formação profissional impelem os adolescentes ao subemprego e ao exercício de atividades de baixa remuneração e precárias condições de trabalho (Muller et al., 2009). Além disso, é importante considerar o caráter estigmatizante do cumprimento de uma medida socioeducativa, o que promove ainda mais escassez de oportunidades de inclusão (Muller et al., 2009; Souza \& Venancio, 2011).

Em conjunto, esses resultados confirmam o quanto os projetos futuros são influenciados pelas condições socioeconômicas e culturais presentes nos contextos em que os adolescentes se desenvolvem, uma vez que as oportunidades são vistas através das condições sociais concretas que a família e a comunidade oferecem. Assim, os projetos revelados pelos adolescentes acabam reproduzindo a condição de exclusão social 
vivenciada tanto no contexto familiar quanto no contexto comunitário (Liebesny \& Ozella, 2002).

No entanto, é importante considerar que os projetos futuros são, ao longo da vida, modificados e transformados, pois estão em permanente adaptação às situações vivenciadas durante todo o processo de desenvolvimento (Teixeira, 2005). Nesse sentido, o cumprimento de uma medida socioeducativa pode ser considerado como uma oportunidade para a revisão desses projetos futuros à medida que adolescentes e famílias recebam suporte para superar as condições de exclusão.

Diante disso, a doutrina da proteção integral, principal diretriz do Estatuto da Criança e do Adolescente - ECA (Lei n. 8.069, 1990) e eixo norteador do Sinase (Brasil, 2006), mostra-se muito pertinente, pois parte do pressuposto de que a garantia de direitos e a oferta de oportunidades podem prevenir a prática de atos infracionais. Assim, o cumprimento de uma medida socioeducativa prevê a inclusão em políticas públicas de saúde, educação, profissionalização e assistência social, de modo a promover a cidadania de adolescentes em conflito com a lei e suas famílias.

Apesar de essas diretrizes gerais mostrarem-se bastante pertinentes, é necessário oferecer um atendimento socioeducativo individualizado, que seja capaz de identificar as fragilidades e potencialidades de cada caso específico, considerando o adolescente e o contexto familiar e comunitário (Brasil, 2006). Com relação aos adolescentes em conflito com a lei, é necessário conhecer os projetos futuros deles e oferecer condições para que esses jovens possam questioná-los e/ou efetivá-los. Os resultados aqui relatados reforçam a necessidade de individualização da execução das medidas socioeducativas, pois os adolescentes investigados demandam estratégias de atendimento que estejam de acordo com suas demandas específicas e relativamente diferenciadas, apesar de vivenciarem um mesmo contexto de privação de liberdade.

Com base nisso, entende-se que os adolescentes que apresentaram projetos positivos e concretos, como ter uma família, estudar e trabalhar, precisam ser incentivados a realizá-los e receber suporte por meio da inclusão em políticas de educação, profissionalização, trabalho e renda. Os adolescentes que apresentam projetos ainda vagos precisam ser estimulados a construir objetivos mais concretos por meio de acompanhamento psicossocial, para então receberem suporte que vise à efetivação deles. Finalmente, o caso do adolescente que possui um projeto de vingança merece atenção especial, pois trata-se de um objetivo bastante negativo que pode apontar indícios de dificuldades mais sérias, o que exigirá uma intervenção focal que vise à superação dos efeitos prejudiciais da severa violência vivida em seu contexto familiar.

Por fim, salienta-se a responsabilidade das instituições socioeducativas em identificar os projetos futuros dos adolescentes para que as intervenções sejam condizentes com eles, oferecendo suporte tanto para a (re)construção quanto para a efetivação dos projetos futuros dos jovens institucionalizados. Para isso, é possível buscar inspiração em experiências bem-sucedidas na promoção de inclusão social e no resgate da cidadania de adolescentes em conflito com a lei, as quais valorizam as demandas específicas dos jovens, o estabelecimento de relações pessoais significativas entre adolescentes e 
profissionais, a aproximação entre o contexto socioeducativo e o contexto comunitário, e, ainda, a inserção dos adolescentes em espaços sociais "extramuros" (Aranzedo \& Souza, 2007; Costa, 2005).

\section{Referências}

Andrade, C. (2010). Transição para a idade adulta: das condições sociais às implicações psicológicas. Análise Psicológica, 28(2), 255-267.

Aranzedo, A. C., \& Souza, L. (2007). Adolescentes autores de homicídio. Vivência da privação de liberdade e planos para o futuro. Revista Eletrônica Psicologia e Política, 5(15), 1-20.

Assis, S. G., \& Constantino, P. (2005). Perspectivas de prevenção da infração juvenil masculina. Ciência \& Saúde Coletiva, 10(1), 81-90.

Branco, B. M., Wagner, A., \& Demarchi, K. A. (2008). Adolescentes infratores: rede social e funcionamento familiar. Psicologia: Reflexão e Crítica, 21(1), 125-132.

Brasil (2006). Sistema Nacional de Atendimento Socioeducativo - Sinase. Brasília: Presidência da República, Secretaria Especial dos Direitos Humanos, Conselho Nacional dos Direitos da Criança e do Adolescente.

Costa, C. R. B. S. F. da (2005). É possível construir novos caminhos? Da necessidade de ampliação do olhar na busca de experiências bem-sucedidas no contexto socioeducativo. Estudos e Pesquisas em Psicologia, 5(2), 79-95.

Lei n. 8.069, de 13 de julho de 1990 (1990). Dispõe sobre o Estatuto da Criança e do Adolescente. Diário Oficial da União, p. 13563.

Liebesny, B., \& Ozella, S. (2002). Projeto de vida na promoção de saúde. In M. L. J. Contini, S. H. Koller \& M. N. S. Barros (Orgs.). Adolescência e psicologia: concepções, práticas e reflexões críticas (pp. 62-67). Brasília: Conselho Federal de Psicologia.

Marcelino, M. Q. dos S., Catão, M. de F. F. M., \& Lima, C. M. P. de (2009). Representações sociais do projeto de vida entre adolescentes no ensino médio. Psicologia, Ciência e Profissão, 29(3), 544-557.

Muller, F., Barboza, P. S., Oliveira, C. C., Santos, R. R. G. \& Paludo, S. S. (2009). Perspectivas de adolescentes em conflito com a lei sobre o delito, a medida de internação e as expectativas futuras. Revista Brasileira Adolescência e Conflitualidade, 1(1), 70-87.

Nunes, M. C. A., Andrade, A. G. de S., \& Morais, N. A. de (2013). Adolescentes em conflito com a lei e família: um estudo de revisão sistemática da literatura. Contextos Clínicos, 6(2), 144-156. 
Paugam, S. (2004). O enfraquecimento e a ruptura dos vínculos sociais: uma dimensão essencial do processo de desqualificação social. In B. Sawaia (Org.). As artimanhas da exclusão: análise psicossocial e ética da desigualdade social (pp. 67-86). Petrópolis: Vozes.

Poletto, M., \& Koller, S. H. (2008). Contextos ecológicos: promotores de resiliência, fatores de risco e de proteção. Estudos de Psicologia, 25(3), 405-416.

Resolução n. 466, de 12 de dezembro de 2012 (2013). Dispõe sobre as diretrizes e normas para pesquisa envolvendo seres humanos. Diário Oficial da União, seção I, pp. 59-62.

Sartório, A. T., \& Rosa, E. M. (2010). Novos paradigmas e velhos discursos: analisando processos de adolescentes em conflito com a lei. Serviço Social \& Sociedade, (103), 554-575.

Sobrosa, G. M. R., Santos, A. S. dos, Oliveira, C. T. de, \& Dias, A. C. G. (2014). Perspectivas de futuro profissional para jovens provenientes de classes socioeconômicas desfavorecidas. Temas em Psicologia, 22(1), 223-234.

Souza, V. L. T. de, \& Venancio, M. M. R. (2011). Os sentidos atribuídos à medida socioeducativa de liberdade assistida por jovens em conflito com a lei e seus socioeducadores. Psicologia da Educação, (32), 163-185.

Teixeira, E. J. (2005). Juventude pobre, participação e redes de sociabilidade na construção do projeto de vida. Dissertação de mestrado, Universidade Federal do Rio de Janeiro, Rio de Janeiro, RJ, Brasil.

Yin, R. K. (2005). Estudo de caso: planejamento e métodos. Porto Alegre: Bookman.

Zappe, J. G., \& Ramos, N. V. (2010). Perfil de adolescentes privados de liberdade em Santa Maria/RS. Psicologia \& Sociedade, 22(2), 365-373.

Submissão: 16.7.2014

Aceitação: 7.12 .2014 